\title{
Do Web Users Care About Banner Ads Anymore? The Effects of Frequency and Clutter in Web Advertising
}

SANG Y. LEE

sang.lee@mail.wvu.edu

Follow this and additional works at: https://researchrepository.wvu.edu/faculty_publications

Part of the Mass Communication Commons

\section{Digital Commons Citation}

LEE, SANG Y., "Do Web Users Care About Banner Ads Anymore? The Effects of Frequency and Clutter in Web Advertising" (2010). Faculty Scholarship. 1167.

https://researchrepository.wvu.edu/faculty_publications/1167

This Article is brought to you for free and open access by The Research Repository @ WVU. It has been accepted for inclusion in Faculty Scholarship by an authorized administrator of The Research Repository @ WVU. For more information, please contact ian.harmon@mail.wvu.edu. 
This article was downloaded by: [Lee, Sang]

On: 7 July 2010

Access details: Access Details: [subscription number 924018945]

Publisher Routledge

Informa Ltd Registered in England and Wales Registered Number: 1072954 Registered office: Mortimer House, 3741 Mortimer Street, London W1T 3JH, UK

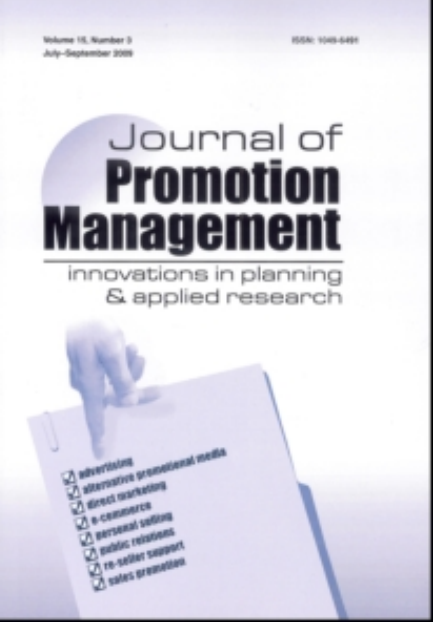

Journal of Promotion Management

Publication details, including instructions for authors and subscription information:

http://www.informaworld.com/smpp/title content=t792306911

\section{Do Web Users Care About Banner Ads Anymore? The Effects of Frequency and Clutter in Web Advertising}

Sang Yeal Lee ${ }^{\mathrm{a}}$; Yong-Suk Cho ${ }^{\mathrm{b}}$

${ }^{\mathrm{a}}$ West Virginia University, Morgantown, West Virginia, USA ${ }^{\mathrm{b}}$ Hansei University, Gunpo-City, South Korea

Online publication date: 07 July 2010

To cite this Article Lee, Sang Yeal and Cho, Yong-Suk(2010) 'Do Web Users Care About Banner Ads Anymore? The Effects of Frequency and Clutter in Web Advertising', Journal of Promotion Management, 16: 3, 288 - 302

To link to this Article: DOI: $10.1080 / 10496490903582594$

URL: http://dx.doi.org/10.1080/10496490903582594

\section{PLEASE SCROLL DOWN FOR ARTICLE}

\footnotetext{
Full terms and conditions of use: http://www.informaworld.com/terms-and-conditions-of-access.pdf

This article may be used for research, teaching and private study purposes. Any substantial or systematic reproduction, re-distribution, re-selling, loan or sub-licensing, systematic supply or distribution in any form to anyone is expressly forbidden.

The publisher does not give any warranty express or implied or make any representation that the contents will be complete or accurate or up to date. The accuracy of any instructions, formulae and drug doses should be independently verified with primary sources. The publisher shall not be liable for any loss, actions, claims, proceedings, demand or costs or damages whatsoever or howsoever caused arising directly or indirectly in connection with or arising out of the use of this material.
} 


\title{
Do Web Users Care About Banner Ads Anymore? The Effects of Frequency and Clutter in Web Advertising
}

\author{
SANG YEAL LEE \\ West Virginia University, Morgantown, West Virginia, USA \\ YONG-SUK CHO \\ Hansei University, Gunpo-City, South Korea
}

\begin{abstract}
This study investigates the effects of frequency of exposure to banner ads and ad clutter in web pages upon online users' psychological responses. In a 7 (frequency 1 through 7) $\times 2$ (cluttervs. non-clutter) between-participants factorial experiment, participants $(N=250)$ were randomly assigned to one of fourteen news websites, each with 20 separate pages of news stories and animated banner ads downloaded from various websites. Results indicated that frequency of exposure is a powerful psychological cue affecting users' memory, attitudes, and behavior. However, contrary to expectation, banner clutter does not lead to negative effects on recall, attitudes, and behavior. Negative impact of banner clutter was significant only on ad recognition.
\end{abstract}

KEYWORDS banner advertising, frequency, repetition, internet, tedium

\section{INTRODUCTION}

Even though frequency of exposure is a major determinant to advertising effectiveness, it still remains a relatively unexplored variable in the realm of web advertising. Perhaps, this is because the impact of frequency of exposure on the web is difficult to track with any degree of accuracy, especially given the complication of clutter on modern-day websites. Although frequency has been extensively researched in advertising over the last several decades, its exact role in terms of advertising effectiveness is difficult to

Address correspondence to Sang Yeal Lee, PhD, Perley Isaac Reed School of Journalism, 304 Martin Hall, West Virginia University, Morgantown, WV 26506. E-mail: sang.lee@ mail.wvu.edu 
assess (Pechmann \& Stewart, 1988). It might be because there are too many variables that mediate the effects of frequency such as types of media, creative executions, and exposure environments, to name only a few. Needless to say, understanding the function of frequency on advertising effectiveness is theoretically and practically important. Nevertheless, empirical research on the function of frequency in advertising is very limited to date, especially in the web advertising environment.

Unlike frequency, advertising clutter has generally been viewed as a factor inhibiting (rather than enhancing) advertising effectiveness, in terms of both memory (Webb \& Ray, 1979; Mord \& Gilson, 1985) and attitude toward ads (Ha, 1996; Speck \& Elliott, 1997). However, research has shown that the negative effects of clutter are often conditioned by other variables such as brand familiarity (Webb, 1979), individual differences (Ha), length of advertisement (Mord \& Gilson), and involvement (Cobb, 1985). The current investigation is an attempt to pinpoint the distinct as well as combinatory effects of frequency and clutter in a typical web advertising environment.

\section{Effects of Frequency/Repetition on Advertising Response}

The emphasis on frequency in advertising comes primarily from the general belief that repetition will increase advertising effectiveness in terms of recall and recognition of the message (Cacioppo \& Petty, 1979; Belch, 1982) and affect message recipients' attitudes toward a brand or purchase intention (Cacioppo \& Petty, 1979, 1980). The general belief that repetition will increase memory of the message can be explained in terms of accessibility of the information (Higgins, 1996). Thus, repeated exposure to the same ads can result in higher accessibility of information relevant to those particular ads and, thereby, increase the likelihood that the stored information can be activated.

Perhaps the most popular theories to explain the function of repetition are the three-hit theory (Krugman, 1972) and the two-factor theory (Berlyne, 1970). For example, the three-hit theory posits that an ad reaches maximum effectiveness at the third exposure. Krugman further argued that "there is no such thing as a fourth exposure psychologically; rather, fours, fives, etc., are just repeats of the third-exposure effect." Thus, the three-hit theory can be thought of as an S-shaped response curve. On the other hand, the two-factor theory by Berlyne predicts an inverted-U curve as a function of frequency in advertising effectiveness. According to this theory, advertising repetition can take the form of an inverted-U curve in which there are two separate opposing psychological processes operating simultaneously: "positive habituation" and "tedium." Berlyne argues that positive habituation can lead to an increase in affect with diminishing returns of each additional exposure, while tedium sets in as a result of repetitive exposure, which would decrease affect gradually. Similar explanations of an inverted-U curve function 
of repetition were proposed by Cacioppo and Petty's (1979) dual processing model of attitudes and by Pechmann and Stewart's (1988) two-stage learning model. Pechmann and Stewart also explain the inverted-U curve response of advertising in terms of "wearin" and "wearout." According to them, in the first stage, wearin occurs during approximately the first three exposures, whereas at the third exposure, positive thoughts finally outnumber negative thoughts. The second stage begins with approximately the fourth exposure where message recipients become bored. As a result, message recipients generate negative repetition-related thoughts, undermining the persuasive impact of the advertisement.

Much of the research on effects of advertisement frequency is restricted to traditional mass media. At this time, it is not clear how the frequency of exposure affects advertising effectiveness in the web environment. One study by Johnson and Neath (1999) showed that repetition of a banner ad within multiple webpages can improve memory of less familiar as well as familiar brands. The findings from this study, along with theory and research pertaining to frequency effects on memory of traditional media advertisements (Rethans, Swasy, \& Marks, 1986), lead us to propose the following hypotheses:

H1a $\boldsymbol{E}$ b: Advertising repetition will have a positive impact on (a) ad recall and (b) ad recognition on the web.

Past research has also demonstrated that frequency can affect attitudes and behavior of message recipients. The mere exposure effect (Zajonc, 1968), for example, posits that a mere increase in frequency of exposure to stimuli would increase positive affect toward those stimuli. A meta-analysis performed by Bornstein (1989) indicated that the mere exposure effect is a "robust" phenomenon in human cognition and that preferences could be formed without conscious awareness of preference-formation. Further, researchers have demonstrated that advertising repetition can encourage a consumer to have a more favorable attitudes toward the brand and buying decision, even when the consumer cannot recall being exposed to the advertisement (Janiszewski, 1993; Shapiro, McInnis, \& Heckler, 1997). Janiszewski, for example, found that incidental exposure to an advertising message could increase consumers' liking for the ad and brand even if they failed to recognize the ad they saw. Some researchers (c.f., Murphy \& Zajonc, 1993) have suggested that affective and cognitive processing could be separated and handled by different neurological systems, and affective processing could be accomplished without cognitive processing. The effects of mere exposure, however, are not necessarily linear. Zajonc (1968) reported that there is a saturation point where the effects of mere exposure reach a "plateau." A follow-up investigation by Kail and Freeman (1973) supported Zajonc's study by indicating a decrease in affective response that resulted in the inverted-U curve formulation. In a review of more than 200 studies, Bornstein (1989) 
concluded that the data showed a non-linear effect of mere exposure. He argued that, after about 10 to 20 exposures, the effects of mere exposure begin diminishing.

Although there is still a lot of debate as to the precise location of the threshold point at which the effects of frequency begin to decline, researchers in general agree that frequency can have a positive impact on attitude toward ad, attitude toward brand (Cacioppo \& Petty, 1979; Mitchell \& Olson, 1981; Rethans et al., 1986) and purchase intention (Cacioppo \& Petty, 1979; Mitchell \& Olson; Belch, 1982; Rethans et al.; Machleit \& Wilson, 1988). Therefore, we propose that:

H1c $\boldsymbol{E} \boldsymbol{d}$ (continued): Advertising repetition will have a positive impact on (c) attitude toward ad, (d) attitude toward brand, and (e) trial intention.

\section{Effects of Clutter on Advertising Response}

Contrary to the effects of repetition, advertising clutter has been traditionally viewed as a threat to advertising effectiveness (Webb \& Ray, 1979; Mord \& Gilson, 1985; Ray \& Webb, 1986). One of the problems of today's internet is that there is simply too much information to view on a given topic. Furthermore, many websites feature numerous banner ads on a single page, occupying all parts of the screen, leading to concerns about ad clutter on websites. Since websites are cluttered with banner ads, such excessive amounts of advertising information may overload consumers with a large quantity of information, much more than what they can handle (Mord \& Gilson; Ray \& Webb, 1986; Razzouk \& Seitz, 2003; Rosenkrans, 2006; 2007; 2009). Although human beings can process multiple pieces of information simultaneously, advertising clutter on the internet can test users' cognitive capacity and, thereby, affect advertising effectiveness. According to industry estimates, U.S. consumers are exposed to up to five thousand advertising messages every day, many of them internet-based marketing appeals (Gurău, 2000).

This raises serious concerns regarding clutter and cognitive capacity. According to Conklin (1987), when internet users are faced with a large number of choices, then "these choices could engender a certain overhead of metalevel decision making." He calls this "cognitive overload." In fact, Johnassen and Wang (1993) have identified the cognitive overload phenomenon as a common problem in the internet environment.

When users on the internet face cognitive overload, they usually find a way to cope with it. Feinberg and Murphy (2000) argue that users may simply reduce cognitive strain by dumping parts of information, rather than trying to find a way to efficiently process all the information that led to the cognitive load in the first place. Given the complexity of the webpage structure that combines various informational elements in one page, advertising clutter on the web can be a factor contributing to user's cognitive overload. 
In addition to the cognitive overload phenomenon, the negative effects of ad clutter on websites can be explained in terms of interference theory. McGeoch (1942) suggested that competing messages interfere with one another and inhibit human learning. In other words, learning new information can interfere with information previously learned, that is, "retroactive interference," or vice versa, that is, "proactive interference" (McGeoch, 1942). It may be argued, then, that cluttered ads in some sense compete with each other or with other elements in a webpage to be processed by users, even when brands in the ads on a webpage do not belong to the same category, as is often the case. Given the nature of the web that often displays multiple banners with same sizes and shapes, ad clutter can hinder the processing of information contained in a specific banner. It is possible that the similarity of the ads in the same vehicle can cause interference between the ads, thereby adversely affecting the memory of the ads. Given that the majority of the literature suggests a negative impact of ad clutter on memory, we propose:

$\boldsymbol{H} 2 \boldsymbol{a} \boldsymbol{E} \boldsymbol{b}$ : Ad clutter will have a negative impact on (a) ad recall and (b) ad recognition.

So far, little empirical research is available for the impact of ad clutter on attitudinal and behavioral outcomes. Ha (1996) found that magazine ad clutter negatively affects attitudes toward advertising. In a study of magazine and television advertising clutter, Speck and Elliott (1997) suggested that ad clutter impairs search for content (binder search), interrupts processing (disruption), and degrades the quality of media processing (distraction), which would create negative attitudes toward advertising and media. Elliott (1998) also showed that perceived ad clutter was related to less favorable attitude toward advertising. The empirical evidence from these few studies suggests that ad clutter can have a negative effect on attitudes and behavior. Therefore, the following hypotheses are proposed:

H2c, $\boldsymbol{d}$, $\boldsymbol{E} \boldsymbol{e}$ (continued): Ad clutter will have a negative impact on (c) attitude toward ad, (d) attitude toward brand and $(e)$ trial intention.

\section{METHOD}

The research questions and hypotheses were investigated using a controlled lab experiment that employed real-world web stimuli. A fully-crossed $7 \times$ 2 between-participants design ( 7 levels of frequency and 2 levels of clutter) was used in the experiment. 


\section{Participants}

Two hundred and fifty undergraduate students (150 females and 100 males) enrolled in communication classes participated in the experiment for extra credit. Participants were randomly assigned to one of fourteen conditions and were exposed to an experimental website. At the time of recruiting, participants were told that the study concerned students' using the internet to learn. All participants signed an informed consent form prior to their participation in the experiment. Participants ranged in ages from 18 to 37 years, with a median age of 20 .

\section{Stimulus Website}

Fourteen experimental news websites were created for this study. To increase external validity, all the ads and news stories were obtained from the CNN Interactive website. The websites were designed to look similar to $\mathrm{CNN}$ Interactive: The CNN logo appeared on the upper left corner, and other common links from the CNN Interactive website also appeared on left- and right-hand sides with slight modification. Each of the fourteen websites contained 20 news stories, most of them downloaded from the CNN Interactive website. News stories were carefully selected to avoid content effects. Each news story was then edited to have 150 200 words in order to make it fit on one page.

For stimulus banners, a pretest was conducted to select moderateinterest brands to college students. In order to rule out ad-specific effects, two stimulus brands were chosen for this study: United Airlines and DirecTV. In designing stimulus banners, three different banners for each stimulus brand were downloaded from the web and then combined as one $(468 \times 60$ pixels). The stimulus banners were not placed in the first or last page to avoid primacy or recency effects. Further, each condition had two versions with different orders of banners, in order to minimize order effects. Each webpage contained one animated banner placed at the top: either a stimulus or non-stimulus banner.

\section{Experimental Treatment Conditions}

For frequency conditions, stimulus banners were inserted according to the frequency condition (see Table 1). In frequency one condition, for example, two stimulus banners (one each of United Airlines and DirecTV) along with 18 non-stimulus banners were inserted into 20 different webpages. Likewise, in frequency seven condition, 14 stimulus (seven United Air ads and seven DirecTV ads) and six non-stimulus banners were inserted into the 20 different webpages. 
TABLE 1 Number of Banners Used in Stimulus Websites

\begin{tabular}{lcc}
\hline $\begin{array}{l}\text { Frequency } \\
\text { Condition }\end{array}$ & $\begin{array}{c}\text { Non-Clutter Condition } \\
\text { Non-target stimulus banner } \\
\text { ads (target ads)* }\end{array}$ & $\begin{array}{c}\text { Clutter Condition Non-target } \\
\text { stimulus banner ads } \\
\text { (target ads) }+ \text { Clutter ads }\end{array}$ \\
\hline 1 & $18^{* *}(2)$ & $18^{* *}(2)+4 \times 20^{* * *}$ \\
2 & $16(4)$ & $16(4)+4 \times 20$ \\
3 & $14(6)$ & $14(6)+4 \times 20$ \\
4 & $12(8)$ & $12(8)+4 \times 20$ \\
5 & $10(10)$ & $10(10)+4 \times 20$ \\
7 & $8(12)$ & $8(12)+4 \times 20$ \\
\hline
\end{tabular}

* The two target ads used in this study were United Airlines and DirecTV.

** stimulus ads: $468 \times 60$ pixel banners.

*** clutter ads: $120 \times 60$ pixel banners.

NOTE: Participants in all 14 conditions were exposed to 20 stimulus banner ads of size $468 \times 60$. Of these, some were target ads, depending on the frequency condition, and are indicated in parenthesis. The remaining ads, whose number is indicated to the left of the parentheses, were banner ads of the same size but were not target ads. They advertised a variety of other products and were never repeated. In addition, in the Clutter conditions, each of the 20 pages in a given condition's website consisted of four so-called Clutter ads that were smaller in size $(120 \times 60)$. See Figures 1 and 2 .

In developing clutter conditions, four different small banners $(120 \times 60$ pixels) were inserted into each webpage: two banners on the left and the other two on the right. Therefore, the only difference between clutter and non-clutter conditions is that the former had these four small banners on the webpage, whereas the latter did not. Except for these frequency and clutter manipulations, the content on all 20 pages of each one of the 14 websites was held constant. Finally, experimental webpages were uploaded to four different ftp sites for easy retrieval of webpages during experimental sessions.

\section{Procedure}

The experiment was administered to groups of participants in a computer lab, which had a series of computers with high-speed internet connection. Upon arriving at the lab, participants were welcomed and asked to sign the informed consent form. They were then told that they would read a series of news websites. Participants were also told that each webpage will automatically roll over to the next one after a preset amount of time, and that they could use the mouse only when they needed to scroll down a webpage. After viewing all the webpages, participants were asked to fill out the study questionnaire.

\section{Dependent Measures}

The dependent variables used in the study were Ad Recall, Ad Recognition, Attitude toward Ad, Attitude toward Brand, and Trial Intention. A free 


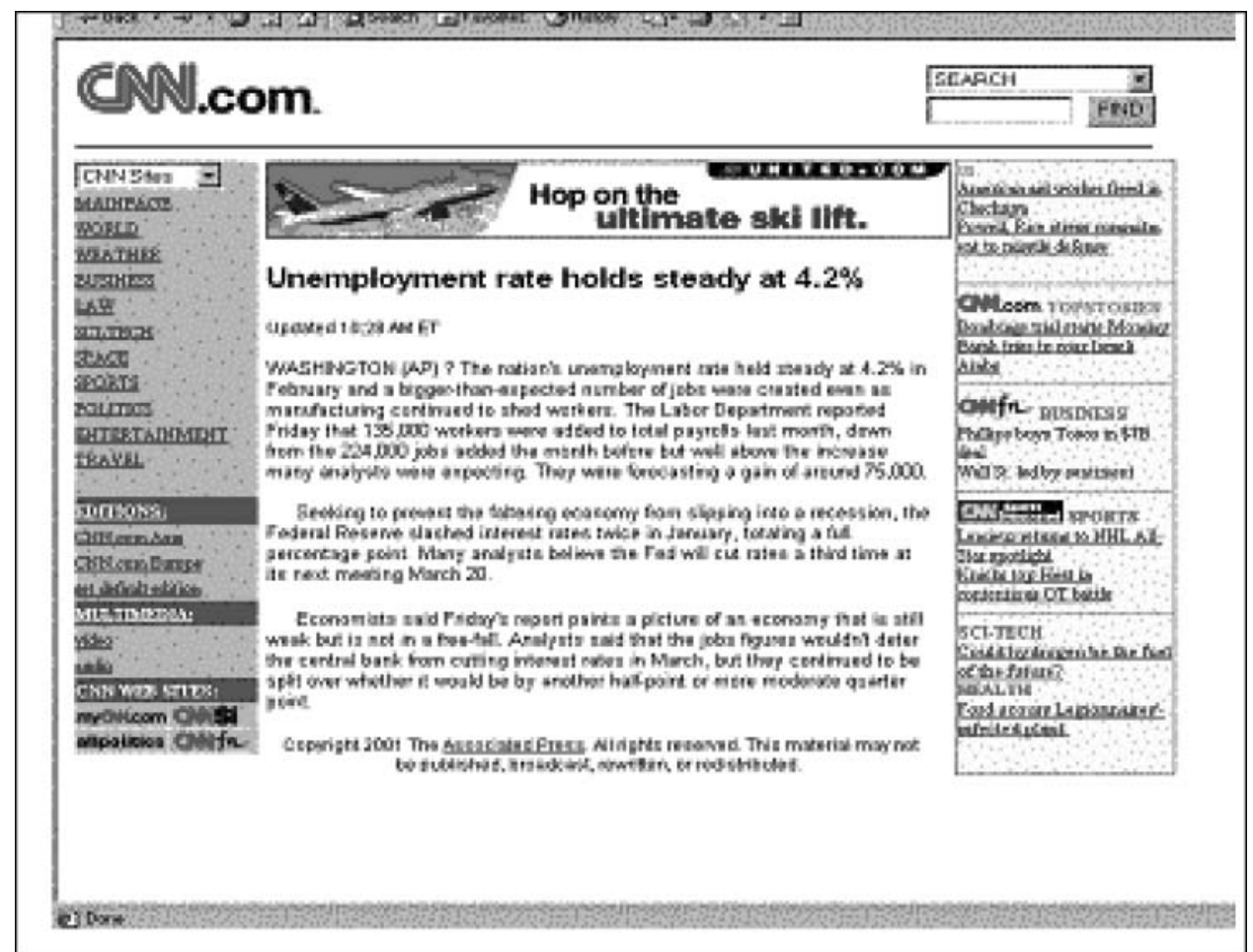

FIGURE 1 Sample webpage in non-clutter condition.

recall question (e.g., Please list as many ads as you can recall from the webpages you visited today) was asked to measure participants' recall for the ads. For Ad Recognition, a series of eight multiple choice, closed-ended questions were used for each of the two target ads. The first of these questions for each ad asked participants to recognize the brand of the target ad from among a choice of competing brands (i.e., other airlines in the case of United, and other TV services in the case of DirecTV), for example, which one of the following airlines was advertised on the web pages you saw today? (This lone item will, henceforth, be referred to as the Brand Recognition Question). In order to measure attitude toward ad, ten 7-point Likert scale items were derived from Machleit and Wilson (1988). These were good/bad, pleasant/unpleasant, entertaining/unentertaining, favorable/unfavorable, appealing/unappealing, believable/unbelievable, impressive/unimpressive, attractive/unattractive, informative/uninformative, and eye-catching/non eyecatching. Internal consistency analysis for attitude toward ad scale items revealed an alpha coefficient of .97. Attitude toward the brand was measured by the three 7-point Likert scale items used by Muehling and Laczniak (1988): good/bad, unfavorable/favorable, negative/positive. Finally, trial 


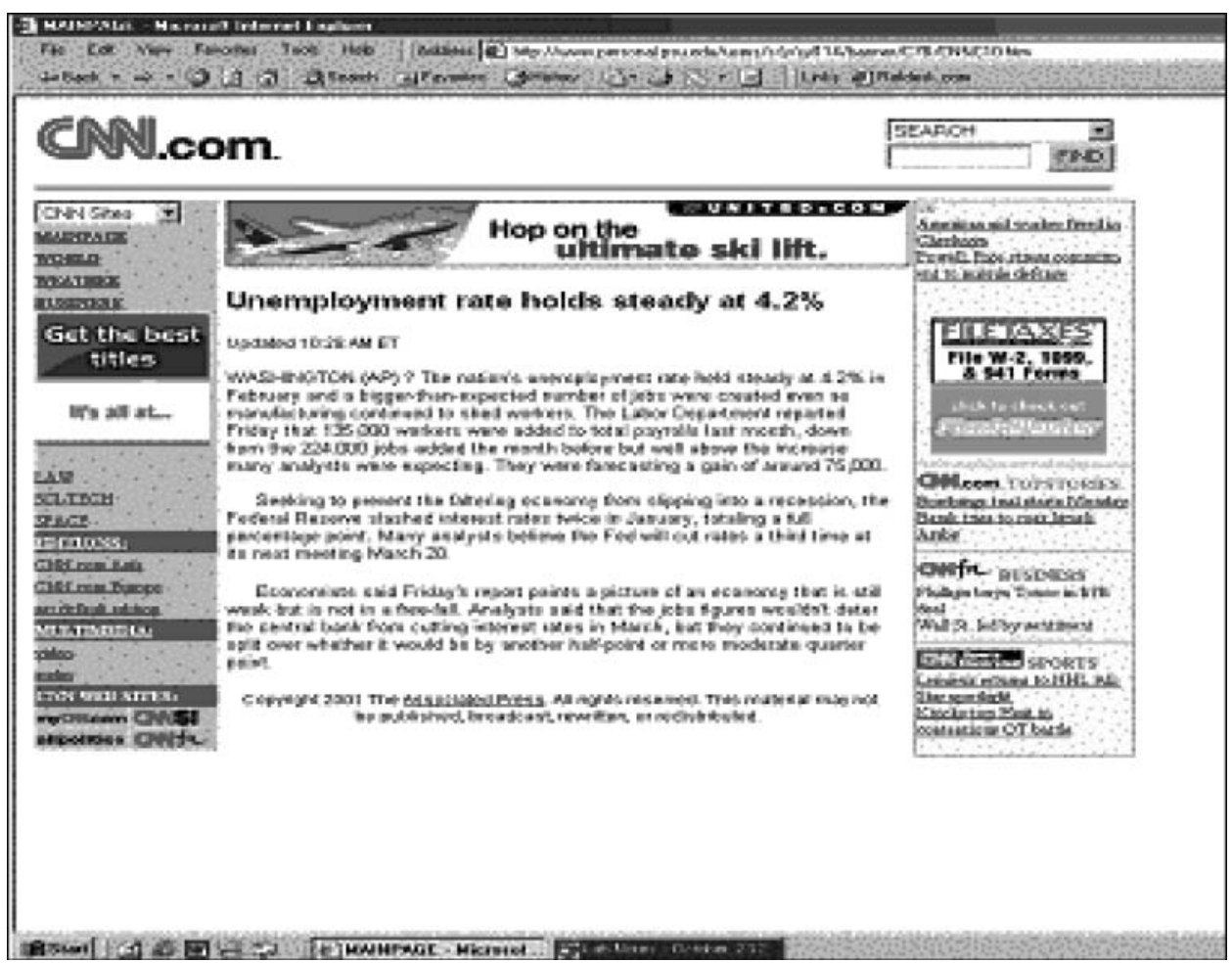

FIGURE 2 Sample webpage in clutter condition.

intention was measured by the three-item 7-point Likert scale anchored between "unlikely" and "likely," used by Yi (1990), for example, what is the likelihood you would buy the product in the ad?

\section{Coding and Analysis}

In coding the data for free recall, subjects who correctly recalled the brand in the stimulus ads were coded as "1." Participants who did not recall the brand correctly but described some details of the ads were coded as "0.5." Participants who did not recall the brands or describe the ads were coded as "0." For recognition, each correct answer was coded as " 1 ," whereas each wrong answer was coded as "0."

For testing hypotheses, an analysis of variance (ANOVA), with seven levels of frequency, two levels of clutter, and self-reported internet experience in years as independent variables, was used. This model was run for each dependent variable separately. In analyzing data for ad recognition, attitude toward ad, attitude toward brand, and trial intention, those 
participants who did not correctly answer the brand recognition question were excluded.

\section{RESULTS}

Hypothesis $1 \mathrm{a}$ and $1 \mathrm{~b}$ predicted positive effects for advertising frequency on both ad recall and ad recognition. The analysis showed a significant main effect for frequency on ad recall, $\mathrm{F}(1,242)=8.31, \mathrm{p}<.005$, but not on ad recognition, $\mathrm{F}(1,72)=2.49, \mathrm{p}>.10$, but both were in the hypothesized positive direction. Therefore, H1a was supported by our data whereas H1b was not. However, it must be noted that the main effect of frequency on ad recognition approached significance $(\underline{p}=0.11)$. Hypothesis 1c predicted positive effects for frequency on attitude toward ad. The analysis failed to support this hypothesis, $\underline{F}(1,72)=1.94, \underline{p}>.10$. For Hypothesis $1 \mathrm{~d}$, which predicted a positive effect for frequency on attitude toward brand, a marginally significant effect emerged, $\underline{F}(1,72)=3.18, \underline{p}=.07$. In addition, there was a significant main effect for frequency on trial intention, $\underline{F}(1,72)=$ 12.36, $\underline{\mathrm{p}}<.001$, thereby lending support to H1e.

Hypothesis 2a predicted a negative effect for ad clutter on ad recall. The analysis failed to support this hypothesis, $\underline{\mathrm{F}}(1,242)=1.92, \underline{\mathrm{p}}>.10$. However, a significant main effect for clutter on ad recognition was obtained, $\underline{F}(1,72)=6.65, \underline{p}<.05$, thus supporting H2b. But, H2c, H2d, and H2e were not supported because effects for clutter on attitude toward ad, $\underline{F}(1,72)=$ $.35, \underline{\mathrm{p}}>.10$, attitude toward brand, $\underline{\mathrm{F}}(1,72)=.73, \underline{\mathrm{p}}>.10$, and trial intention, $\underline{\mathrm{F}}(1,72)=.29, \underline{\mathrm{p}}>.10$, were not statistically significant.

Although we did not predict any interactions, a couple of important two-way interactions were observed. There was a statistically significant interaction between clutter and frequency on attitude toward ad, F $(1,72)=$ 4.30, $\mathrm{p}<.05$. This interaction showed that while frequency did not affect users' attitude toward ad in a non-cluttered environment, frequency of exposure had a positive impact on users' attitude toward the stimulus ads in a cluttered environment. Another interaction, between frequency and level of internet experience on recognition, approached significance, $\underline{F}(1,72)=$ $2.50, \mathrm{p}=.11$. This interaction indicated that when the frequency is low, the level of internet experience did not matter. However, when the frequency is high, the level of internet experience had a positive impact on users' recognition of the stimulus ads.

In sum, results from the analyses suggest that frequency can be a powerful determinant of advertising effectiveness. Specifically, it is found that the frequency effects were significant on ad recall, attitude toward brand, and trial intention. Contrary to our expectations, however, the effects of banner clutter were weak across dependent variables. The clutter effects were significant only on ad recognition. 


\section{DISCUSSION}

The present study investigated the effects of frequency of exposure to banner ads, ad clutter, and the level of internet experience on online users' memory, attitudes, and behavioral intent in web advertising environment. The results of this study have important theoretical and practical implications for web advertising.

A major finding in this study is related to the frequency effects on advertising effectiveness. Our analyses revealed relatively significant frequency effects on ad recall, attitude toward brand, and trial intention. Although the internet provides a somewhat different environment compared to traditional media, our results in general indicate that frequency can be an important determinant of the effectiveness of web advertising. Our results are somewhat consistent with recent studies on the frequency effects on ad recall and ad recognition in an internet environment, as well as earlier studies on frequency effects on attitude toward brand and behavior in traditional media (Janiszewski, 1993; Shapiro et al., 1997).

The results also suggest that despite the widespread concern from the advertising industry on the effects of frequency on advertising effectiveness (Colkin, 2000), frequency can still positively affect users' memory and, further, attitude toward brand and trial intention.

Contrary to our predictions, however, the clutter effects were relatively weak across dependent variables. Our results on the clutter effects are somewhat inconsistent with prior studies on advertising clutter (Webb \& Ray, 1979; Mord \& Gilson, 1985; Ray \& Webb, 1986), which in general resulted in negative clutter effects on ad recall and ad recognition. Past research has demonstrated that the effects of clutter may be moderated by variables such as brand familiarity (Webb, 1979), individual differences (Ha, 1996), length of advertisement (Mord \& Gilson), and involvement (Cobb, 1985). We suspect that one such moderating variable in the internet advertising environment is interactivity. For example, with traditional media such as television or radio, audience members are relatively passive and are forcibly exposed to commercial messages. On the internet, however, users have the freedom to choose the content of a webpage and, therefore, it may be fair to say that they have freedom to process information selectively. Thus, when users on the internet face cognitive overload situation, they would find a strategy to cope with it. That is, they may or may not pay attention to cluttered ads, depending on their cognitive capacity.

Another possible explanation for weak clutter effects might be that internet users may have become accustomed to cluttered webpages. For example, in the context of clutter effects in traditional media, Brown and Rothschild (1993) argue that since advertising clutter has already reached a high level, further increase in clutter is relatively "harmless." This may be true for internet environment, too. As the internet gets mature, users may get used to 
clutter ads on the internet. Thus, clutter ads may not introduce as much noise as one may expect. However, this explanation is somewhat contradictory to cognitive overload (Conklin, 1987) and limited capacity theory (Lang, 2000). One reason for this contradiction might be that banner clutter may consume only a small portion of cognitive resources and may not reach the level sufficient enough to create cognitive overload. Collectively, our study indicates that clutter is not a major threat to advertising effectiveness on the internet.

The two-way interaction between frequency and clutter on attitude toward ad also holds theoretical and practical implications. This interaction indicated that frequency does not matter in the non-clutter condition. However, when the same ad was displayed with other ads cluttering the website, frequency had a significant positive impact. This is somewhat counterintuitive because it contradicts the interference explanation (which suggests a negative cognitive impact of target ad in a cluttered environment). One possible explanation is that, as previously discussed, clutter may have less impact as one would expect in the web advertising environment. It may be possible that strong frequency effects override negative effects of clutter, resulting in a positive attitude toward the ad when the ads are cluttered. However, this does not explain the flat line for frequency effect on attitude toward the ad in the non-clutter environment. Therefore, the positive effect of frequency on attitude toward the ad appears to be exclusive to a cluttered ad environment. We may speculate that the mere-exposure effect in a web advertising scenario is realized only when the stimulus ad is contrasted with a background of nondescript ads that keep changing from page to page. The stimulus ad is the only one that reappears from one page to the other, thereby "standing out" from the crowd. Clearly, further research is needed to test this theoretical proposition based on visual distinctiveness leading to positive attitudes.

\section{Limitations}

This study has some limitations. First, the experiment was conducted in a controlled environment. For example, time was controlled in this study, but this is not realistic in the real world. If users were given more time to browse the webpages, they might display a different navigation behavior. Second, regarding the frequency conditions, our study employed frequency one through seven. Different frequencies may result in different results. Finally, regarding the clutter conditions, only four small banners of the same size were used. Different numbers and shapes of banners may result in different results. Future research should systematically address these externalvalidity limitations of the current experiment.

Future study would also benefit by distinguishing task-oriented users from casual users. Given the fact that one of the most distinctive characteristics of the internet is providing tools, such as search engines that help 
users find specific information, task-oriented versus casual browsing on the internet would make a significant difference in measuring the effectiveness of banner advertising and other forms of persuasive communications in this new medium.

\section{REFERENCES}

Belch, G. E. (1982). The effects of television commercial repetition on cognitive response and message acceptance. Journal of Consumer Research, 9(1), 5665.

Berlyne, D. (1970). Novelty, complexity, and hedonic value. Perception and Psychophysics, 8(5-A), 279-286.

Bornstein, R. F. (1989). Exposure and affect: Overview and meta-analysis of research, 1968-1987. Psychological Bulletin, 106(2), 265-289.

Brown, T. J., \& Rothschild, M. L. (1993). Reassessing the impact of television advertising clutter. Journal of Consumer Research, 20(1), 138-146.

Cacioppo, J. T., \& Petty, R. E. (1979). Effects of message repetition and position on cognitive response, recall, and persuasion. Journal of Personality and Social Psychology, 37(1), 97-109.

Cacioppo, J. T., \& Petty, R. E. (1980). Persuasiveness of communications is affected by exposure frequency and message quality: A theoretical and empirical analysis of persisting attitude change. Current Issues and Research in Advertising, 11(2), 285-329.

Cobb, C. J. (1985). Television clutter and advertising effectiveness. In R. Lusch et al. (Eds.), 1985 AMA Educators' Conference Proceedings (pp. 41-47). Chicago, IL: American Marketing Association.

Colkin, E. (2000, November 27). A mixed message online. Informationweek, pp. 22-24.

Conklin, J. E. (1987). Hypertext: An introduction and survey. IEEE Computer, 20(9), $17-41$.

Elliott, M. (1998). Consumer perceptions of advertising clutter and its impact across various media. Journal of Advertising Research, 38(1), 29-41.

Feinberg, S., \& Murphy, M. (2000). Applying cognitive load theory to the design of web-based instruction. In Proceedings of IEEE professional communication society international professional communication conference and Proceedings of the 18th annual ACM international conference on Computer documentation: Technology \& teamwork (pp. 353-360).

Gurău, C. (2009). Marketing flexibility in the context of the service-dominant logic. Marketing Review, 9(3), 185-197.

Ha, L. (1996). Advertising clutter in consumer magazines: Dimensions and effects. Journal of Advertising Research, 36(4), 76-84.

Higgins, E. T. (1996). Knowledge activation: Accessibility, applicability, and salience. In E. T. Higgins, \& A. W. Kruglanski, (Eds.), Social psychology: Handbook of basic principles (pp. 133-168). New York: Guilford.

Janiszewski, C. (1993). Preattentive mere exposure effects. Journal of Consumer Research, 20(3), 376-392. 
Johnassen, D., \& Wang, S. (1993). Acquiring structural knowledge from semantically structured hypertext. Journal of Computer-Based Instruction, 20(1), 1-8.

Johnson, C. R., \& Neath, I. (1999). The world wide web: Exploring a new advertising environment. CyberPsychology \& Behavior, 2(3), 195-212.

Kail, R. V., \& Freeman, H. R. (1973). Sequence redundancy, rating dimensions, and the exposure effect. Memory and Cognition, 1(4), 454-458.

Krugman, H. E. (1972). Why three exposures may be enough. Journal of Advertising Research, 12(6), 11-14.

Lang, A. (2000). The limited capacity model of mediated message processing. Journal of Communication, 50(1), 46-70.

McGeoch, J. A. (1942). The psychology of human learning. New York: Longmans, Green \& Co.

Machleit, K. A., \& Wilson, D. (1988). Emotional feelings and attitude toward the advertisement: The roles of brand familiarity and repetition. Journal of Advertising, $17(3), 27-35$.

Mitchell, A. A., \& Olson, J. C. (1981). Are product attribute beliefs the only mediator of advertising effects on brand attitude? Journal of Marketing Research, 18(3), 318-332.

Mord, M. S., \& Gilson, E. (1985). Shorter units: Risk-responsibility-reward. Journal of Advertising Research, 25(3), 9-19.

Muehling, D. D., \& Laczniak, R. N. (1988). Advertising's immediate and delayed influence on brand attitudes: Considerations across message-involvement levels. Journal of Advertising, 17(4), 23-34.

Murphy, S. T., \& Zajonc, R. (1993). Affect, cognition, and awareness: Affective priming with optimal and suboptimal stimulus exposures. Journal of Personality and Social Psychology, 64(5), 723-729.

Pechmann, C., \& Stewart, D. W. (1988). Advertising repetition: A critical review of wearin and wearout. Journal of Current Issues and Research in Advertising, 11(2), 285-329.

Ray, M. L., \& Webb, P. H. (1986). Three prescriptions for clutter. Journal of Advertising Research, 26(1), 69-77.

Razzouk, N., \& Seitz, V. A. (2003). Banner advertising and consumer recall: An empirical study. Journal of Promotion Management, 9(1/2), 71-80.

Rethans, A., Swasy, J. J., \& Marks, L. J. (1986). The effects of television commercial repetition, receiver knowledge, and commercial length: A test of the two-factor model. Journal of Marketing Research, 23(1), 50-61.

Rosenkrans, G. (2006). Online banner ads and metrics challenges. International Journal of Internet Marketing and Advertising, 3(3), 193-218.

Rosenkrans, G. (2007). Online advertising metrics. In R. Reynolds, R. Woods, \& J. Baker, (Eds.), (Handbook of research on electronic surveys and measurements (chap XV, pp. 136-143). Hershey, PA and London: Idea Group Reference.

Rosenkrans, G. (2009). The creativeness and effectiveness of online interactive rich media advertising. Journal of Interactive Advertising, 9(2), 18-31.

Shapiro, S., McInnis, D., \& Heckler, S. (1997). The effects of incidental ad exposure on the formation of consideration sets. Journal of Consumer Research, 24(1), 94-104. 
Speck, P. S., \& Elliott, M. T. (1997). The antecedents and consequences of perceived advertising clutter. Journal of Current Issues and Research in Advertising, 19(2), 39-54.

Webb, P. H. (1979). Consumer initial processing in a difficult media environment. Journal of Consumer Research, 6(3), 225-236.

Webb, P. H., \& Ray, M. L. (1979). Effects of TV clutter. Journal of Advertising Research, 19(3), 7-12.

Yi, Y. (1990). Cognitive and affective priming effects of the context for print advertisements. Journal of Advertising, 19(2), 40-48.

Zajonc, R. (1968). Attitudinal effects of mere exposure. Journal of Personality and Social Psychology, 9(2, Part 2), 1-27. 